\title{
Using Eye-Tracking to Measure the Influence of Banner Ads' Browsing Behavior and Attitude on Host Websites
}

\author{
Yu-Ping Chiu \\ Department of Advertising, Chinese Culture University \\ E-mail: qyp2@ulive.pccu.edu.tw \\ Shu-Chen Chang \\ Department of Advertising, Chinese Culture University \\ E-mail: zsz5@ulive.pccu.edu.tw
}

\begin{abstract}
This study used the spillover effects and the reversal theory to examine the impact of website banner on the advertising attitude. This study recruited 146 volunteers to test on a computer program with an eye-tracking device. All participants' eye movements data were recorded and analyzed, and this study also used a psychological scale to measure the participants' attitudes. Results showed that if an advertising banner arouses the viewer's negative attitude, the negative attitude does spill over to the host website. When a viewer has a negative attitude toward a host website, his/her fixation time and revisits intention of the host website will significantly reduce. These findings not only help advertisers in planning advertising strategies but also provide some valuable implications for the website developers.
\end{abstract}

Keywords: Spillover effects, Banner advertising, Advertising attitude, Eye-tracking device, Fixation time

\section{INTRODUCTION}

Online advertising has become extremely popular in recent years. For example, banner ads, pop-up ads, sponsorships, pay-per-click ads, text link ads, advergame, and button advertising are flooding in the webpages (Belanche, Flavián, \& Pérez-Rueda, 2017; Chiu, Lo, \& Hsieh, 2017; Duff \& Faber, 2011). These ads help enterprises build advertisement awareness, brand awareness, brand image, and intent to purchase (Chiu, 2019; Hsu, Chang, Kuo, \& Cheng, 2017; Hwang \& Jeong, 2016; Kang, 2019). Besides, 
the cost of online advertising is much lower than TV and print advertising, but the scope of influence is relatively broad. Therefore, advertisers are likely to use online advertising to deliver product and company information (Chiang, Lo, \& Wang, 2017; Djamasbi, Siegel, \& Tullis, 2010; Voorveld, van Noort, Muntinga, \& Bronner, 2018).

It is interesting to understand how to increase viewers' advertising viewing. For example, previous studies have discussed the influence of size and dynamic of advertising (Kuisma, Simola, Uusitalo, \& Öörni, 2010), the placement of advertising (Faber, Lee, \& Nan, 2004; Kim, Youn, \& Yoon, 2019) and the content and design (Belanche et al., 2017; Namin, Hamilton, \& Rohm, 2020) on click-through rate and purchase intention (Baltas, 2003). Moreover, when banner advertising is consistent with the website context, it will induce more favorable towards the advertising (Romaniuk $\&$ Wight, 2009). Even some scholars have found that viewers have more attention to advertising for highly contrasting colors between background and text (Putrevu \& Lord, 2003).

The existence of online advertising helps the websites to keep web content-free so that viewers are willing to tolerate these advertising. However, too many advertisings not only waste viewer's cognitive resources but also hinder the target task, so gradually treading advertising as a form of unpleasantness and disrupting people's processing of information (Ha \& McCann, 2008; Zhang, Luo, \& Boncella, 2018). When an individual is obstructed by online advertising, in addition to taking some actions to eliminate the avoidance behavior exposed to the advertising, it also leads to a negative attitude (Cho $\&$ Cheon, 2004). Moreover, these negative attitudes may even affect the viewer's perception of the host websites.

Previous studies seldom mentioned the perceptions of banner advertising carried and spilled over to the host websites. It is an essential question since website managers need to make a trade-off between avoiding be hurt by any irritation advertising and ridiculously prevents advertisings that cause short-term income decreasing. As being a selective host of advertising, they need to ensure an appropriate website image in viewers' minds. Once viewers have negative attitudes towards the host website, they are not only refuse to revisit but also spread the negative word-of-mouth (McCoy, Everard, Polak, \& Galletta, 2007). In other words, discussing how the negative advertising attitude affects the perception of the host website is the critical issue of this study.

This study explored the perspective from spillover effects. The spillover effect in economic theory refers to the fact that one aspect of a thing will drive the development of other aspects of things, and some behaviors of specific people or groups will also spill over to irrelevant others. Thota, Song, and Biswas (2012) also suggested that when two different stimuli are combined, the viewers' evaluation of stimuli will shift to 
another stimulus. From the perspective of the Internet situation, since the viewer enters the webpage for the first time, it will be a preconsciously scanning and analyzing the page (Ryu, Lim, Tan, \& Han, 2007). At this time, the behavior that viewers look at the banner advertising regard as a preattention level (Greenwald \& Leavitt, 1984), this preattentive processing will keep the memory without perception. Although it was not a specific memory, viewers may also have a negative emotion and attitude toward banner advertising.

Simultaneously, the websites may also evoke similar perceptions as those feelings generated by the advertising (Balachander \& Ghose, 2003). However, website managers might argue that hosting unknown or unfavorable advertising might not affect all audiences because the relationship between the advertisements and the website is not a permanent nature. They claimed that the banner of advertising posted in a short period and it would change to other advertisings after a while. Although hosting advertisements would get more revenue for websites, website viewers are likely to have unfavorable perceptions and attitudes towards websites that have irritation advertisings. The irritation advertisings resulted in customers' negative perceptions and spilling over to the website. Similarly, negative emotional responses, which arouse from exposure to annoying advertising, could spill over to the evaluation of the host websites (Thota et al., 2012).

Accordingly, this study suggests that viewers are likely to regard this advertising as contextual cues to judge the perception of the host website. Once exposed to annoying advertising, viewers are not only conscious or unconscious to avoid these advertising; such negative attitudes may also spill over to the host website. That is, an unfavorable advertising attitude harms its host websites since it not only results in a negative website attitude but also leads to reduce fixation time and revisit intention.

Moreover, this study also suggests that the spillover effect can be affected by metamotivational states. The metamotivational states indicate that an individual's behavior is generally in the telic or paratelic states. When an individual is in the telic states, they prefer low felt arousal so that they will focus on the subject. At this time, online advertising will disperse their limited cognitive resource on the main content (Bodoff, 2006) and even interrupts the viewer's browsing behavior (Cho \& Cheon, 2004).

Therefore, this study claimed that once viewers are in the telic states, their negative attitude toward the advertising is more likely to spill over to the host website, which makes viewers have a negative attitude towards the website. At this time, it may not only reduce the fixation time to the website but also leave the websites immediately. On the other hand, when viewers are in the paratelic states, although they may unpleasant 
with the irritate from advertising, the negative attitude is relatively slight, which seldom spills over to the website.

This study conducted a laboratory experiment to build a realistic website and banner advertising to measure viewers' browsing behavior. The findings of this study showed that when viewers exposed to annoying advertising, they are not only consciously or unconsciously adopt the avoiding behaviors towards advertising. Their negative attitude will also spill over to the host websites. Moreover, the managerial implications of our findings were also discussed in the last section of this study.

\section{LITERATURE REVIEW}

\section{Online Advertising and Avoidance Behavior}

People immerse in thousands of advertising content in their daily lives, such as television commercials, and banner advertising embedded in webpages (Boateng, 2016; Burns \& Lutz, 2006). The most important and widely used online advertising type is banner advertising (Cho \& Cheon, 2004; Namin et al., 2020). A banner advertising (which typically contains $468 \times 60$ pixels, is embedded in the host websites and cannot be closed) intended to attract viewers flow to another website by animation, sound, and video (Faber et al., 2004; Hussain, Ferdous, \& Mort, 2018).

Banner advertising usually works in two mechanisms: clicks and impressions. The impressions refer to the number of times advertising is viewed and clicked, and cost per mile (CPM) is the most used to calculate the number of impressions. Moreover, it can also calculate by cost per click (CPC), that is, viewers click the advertising. When viewers click on advertisements, the viewer may be redirected to a specific webpage, which is set by advertisers. The content on this webpage is tried to persuade viewers and strengthen the brand or product attitudes and behaviors (Gao, Koufaris, \& Ducoffe, 2004).

It is interesting to understand how to attract the viewers' focus upon advertisements. For example, previous studies have discussed the relationships among the influence of size and dynamic of advertising (Kuisma et al., 2010), the placement of advertising (Faber et al., 2004) and the content and design (Lohtia, Donthu, \& Hershberger, 2003), and the click-through rate and purchase intention. Moreover, when banner advertising is consistent with the website context, it will induce more favorable attitudes towards advertising (Moors \& De Houwer, 2006). Even some researchers have found that viewers would get more attention to highly contrasting colors advertising between background and text (Putrevu \& Lord, 2003). However, some studies suggested that people are likely to ignore advertisements while they are focused on specific activities (Duff \& Faber, 2011). Stafford and Stafford (2002) indicated that people would ignore, flip, or skip their viewing of advertising because these advertising 
content tried to convince them. This process is called advertising avoidance (Duff \& Faber, 2011).

Because viewers would perform avoidance behaviors when they were focusing on specific activities, advertising disturbing into activities would arouse viewers' negative emotions, even angry. These negative emotions and attitudes might further affect the viewer's perceptions toward the brand, and the attitudes toward the host websites $(\mathrm{Li}$, Edwards, \& Lee, 2002). This study explores this phenomenon for the effect of advertising spillovers.

\section{Advertising Spillover Effects}

The spillover effects refer to the fact that one aspect of the thing will drive the development of other aspects of the things. The reason is that one aspect of the thing will leave relevant nodes in the individual's mind, and this node will follow nodes in other networks that are connected, but the affected differently by the strength of the connection. Also, some behaviors of specific people or groups will spill over to unrelated others (Balachander \& Ghose, 2003).

Thota et al. (2012) also used spillover effects to explain how evaluations of one stimulus are transferred to another when the two stimuli are presented in conjunction with each other. The possible reasons may be that when individuals are stimulated by something, they enter into the level of preattention, and this stage of preattentive processing has an unclear memory and attitude toward the subject(Greenwald \& Leavitt, 1984). Moreover, in brand alliances, spillover effects are expected to be mostly positive because it does not make strategic sense to form permanent alliances with a brand that possesses a negative image. Several scholars have also explored the fact that after the exposure of advertising, in addition to increasing the exposure of their brands, it will also produce an indirect effect on other similar competitive brands.

However, the Internet context does not seem to be the case. From the perspective of the webpage, in addition to the content built by the host websites, is also includes banner advertising placed by other advertising agencies. When viewers conducting the subliminal scan on the specific block in the webpage, they will determine which blocks belong to the primary information, and which blocks belong to banner advertising. According to the spillover effect, this study suggests that the presence of banner advertising may serve as contests to affect host websites' perception and attitude. That is, the websites may also evoke similar feelings and perceptions as those generated by banner advertising (Thota et al., 2012). Because the relationship between banner ads and its host site is not permanent, the spillover effect of advertising on the websites could be either positive or negative. Mostly it will spill its negative image to the host site. 
When viewers conducting the subliminal scan to the context with banner advertising, their cognitive resources are consumed and hinder the target task (Olivers \& Humphreys, 2002), and even interrupt the browsing target (Cho \& Cheon, 2004). At this time, in addition to avoidance behavior was happened, viewers often have negative attitudes towards these advertising that interfere with their browsing behavior (Thota et al., 2012). This study suggested that viewers will regard banner advertising as the contextual clue and further extend their negative attitude to the host websites, and then influence the evaluation and attitude of the website. Accordingly, this study proposes the following hypothesis:

H1: Viewers exposed to banner advertising with negative attitudes will result in negative attitudes towards the host website.

Previous studies have pointed out that when viewers have a negative attitude towards the host websites, it will reduce the fixation time (McCoy et al., 2007). However, the perspective of the discussion is that the negative attitude induces from the main content and structure, the spillover effect from negative attitudes towards banner advertising has not been discussed yet. Therefore, this study suggests that when viewers disturbed by banner advertising, the negative attitudes towards the host websites would increase and reduce the fixation time viewers stay on this website. Hence, this study proposes that:

H2: Viewers who have negative attitudes towards the host websites will reduce their fixation time stay on a website.

When viewers have negative emotions and attitudes towards the host websites, in addition to the bad and angry feeling (Burns \& Lutz, 2006; Gao et al., 2004), it may also reduce the willingness to revisit the websites (McCoy et al., 2007). That is, this study proposes that when negative attitudes towards the advertising spill over to the host websites, it will also reduce the willingness to revisit the website.

H3: Viewers who have negative attitudes towards the host websites will reduce their intent to revisit.

\section{Reversal Theory}

Reversal theory indicates that there are two different phenomenological states of mind, the telic and paratelic states (Deng \& Poole, 2010). The telic/paratelic states are mutually exclusive. It is related to the degree of feeling arousal, and these two states 
will affect the attitude and feelings of the individual in different ways (Stanaland \& Tan, 2010). For example, an individual is serious-minded, goal-oriented, and arousalavoidant in telic states. They are in low felt arousal and prefer relaxation and calmness. Once the high felt arousal happened, they may feel anxious and angry (Stanaland \& Tan, 2010). Therefore, in addition to the content related to the topic, other messages are aware of disturbing with the goal achievement and reduce the attention towards peripheral stimulation (Janiszewski, 1998).

On the other hand, in paratelic states, the individual is playful-minded, hedonistic, and arousal-seeking. High arousal in this state is experienced as delightful because it is related to excitement, whereas low arousal will be unpleasant and is described in the light of boredom (O'Connell \& Calhoun, 2001). That is, the individual is more likely to influence from peripheral objects when in paratelic states.

Deng and Poole (2010) further divided the telic-paratelic state into two different types of Internet activity: goal-oriented web search behaviors and nondirected experiential web browsing activities. When the individual is in telic states, they usually actively engaged in a specific target search activity, such as searching for specific product information or actual products on Internet (Bodoff, 2006; Deng \& Poole, 2010). At this time, the appearance of advertising may reduce individual's limited cognitive resources (Olivers \& Humphreys, 2002), and then interrupt the target content they are looking for (Cho \& Cheon, 2004), and generate a higher degree of intrusion and anger (Thota et al., 2012). This study suggests that viewers will spill their negative attitudes towards advertising to the websites in telic states.

On the other hand, when viewers are in paratelic states, enjoyment and entertainment-related content are sought (Bodoff, 2006; Deng \& Poole, 2010). At this time, because they do not have the specific and exact content to search, even surrounding advertising interferes with their browsing behavior will not lead to negative emotion and attitude. Therefore, this study proposes that:

H4: Compared to paratelic states, viewers have a significant spillover effect on the host websites when they are in telic states.

As mentioned above, when viewers are in telic states, they will produce more negative attitudes toward advertising, and then spill over this attitude towards the website. This negative attitude will further reduce the fixation time towards the host websites. Therefore, this study suggests that viewers' fixation time towards the host websites have significantly lower on telic states than on paratelic states. Therefore, this study proposes that: 
H5: Compared to paratelic states, viewers' fixation time towards the host websites have significantly different when they are in telic states.

Moreover, this study also suggests that viewers' revisit intention towards the host websites have a significant difference between telic and paratelic states. When they are in telic states, they will produce more negative attitudes toward advertising, and then spill over this attitude towards the website. At this time, it will also reduce the willingness to revisit the websites than paratelic states. Therefore, this study proposes that:

H6: Compared to paratelic states, viewers' revisit intention towards the host websites have significantly different when they are in telic states.

\section{METHODOLOGY}

This study invited volunteers to a laboratory to facilitate experimental control for investigating the influence of banner ads' browsing behavior and attitude on host websites. A laboratory experiment was used for the following reasons. First, to emphasize the advertising spillover effect, the banner advertising and the webpage content were manipulated. Second, systematic differences among participants and the environment of the experiment that can affect the outcomes can be eliminated in experimental laboratory design, enabling all differences in outcomes to be attributed to experimental treatments (Keppel, 1991). In other words, experimental materials can be manipulated identically in both control and experimental groups, minimizing the opportunity of extraneous and unwanted sources of systematic variance to influence the outcomes (Chiu et al., 2017; Kerlinger \& Lee, 2000). Thus, a laboratory experiment was more suitable than a field experiment.

This study used an eye-tracking device to record and analyze participants' eye movement data. Many scholars have already used this device to examine Internet scanning behavior (Harrar, Le Trung, Malienko, \& Khan, 2018; Lee \& Ahn, 2012; Tangmanee, 2016), evidence that it is an effective method. All participants joined the experiment and signed a form indicating that they permitted the eye movement data collected.

\section{Procedure}

The experiment consisted of three phases, in which participants were unaware of the purpose of the experiments until they had completed all phases. First of all, participants were notified that the device was used to record their eye movement path while they viewed the webpage. The participant then goes through the pupil calibration 
process, which enables the eye tracking device to precisely note their eye movements path while browsing the webpage. During the calibration process, the system will record the pupil center-corneal reflection relationship as corresponding to a specific $\mathrm{x}, \mathrm{y}$ coordinate on the screen (Lin, Zhang, \& Watson, 2003; Mulvey, Zemblys, Larsson, \& Holmqvist, 2014). To ensure that fixation on locations was recorded accurately, participants' eye locations were calibrated in relation to nine points arranged in a grid pattern.

Second, participants were assigned to view the specific blog, which included a text area and banner advertising. All participants were exposed to a webpage for $2 \mathrm{~min}$, which was the average time spent reading webpage content according to a pilot test. Third, after the eye tracking device recorded participants' eye movements, they have to evaluate their advertising and webpages attitudes. Once the participants completed the experiment, we will tell them the research purpose. (see Figure 1)

\section{Figure 1. The Laboratory Experiment and Eye Tracking Device}
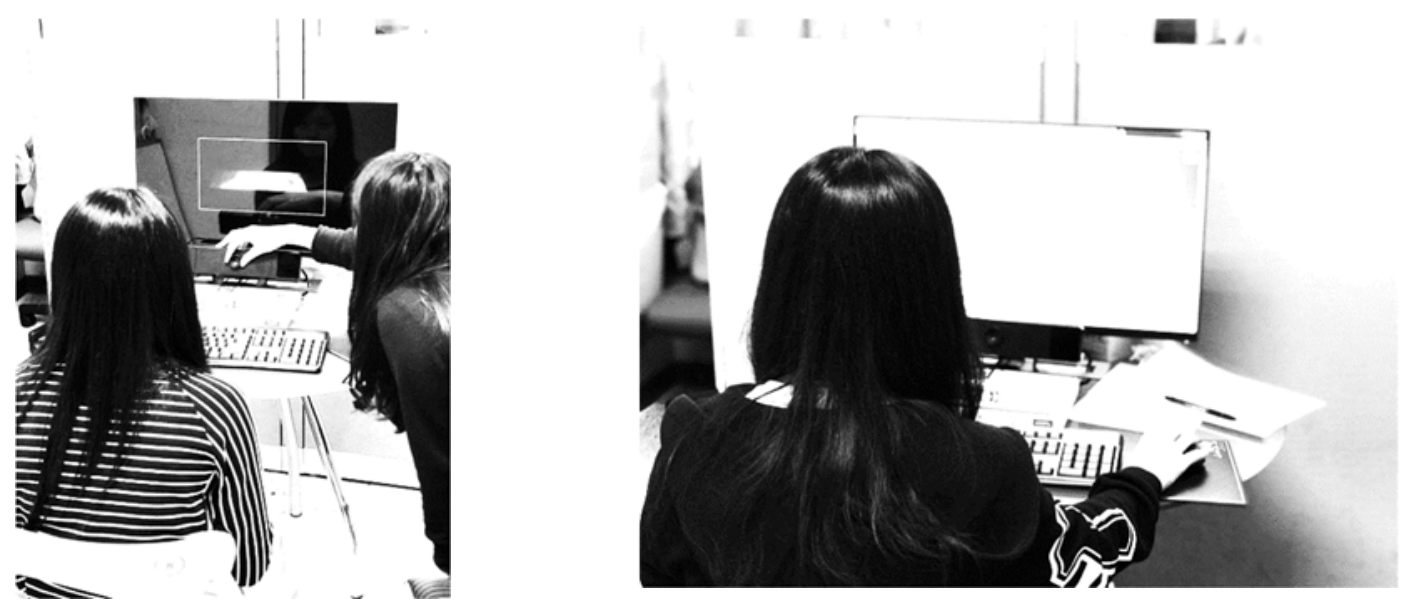

\section{Materials}

\section{Manipulating the host website's content}

A blog platform was used as the host page for establishing an experimental situation that evoked real viewing behavior. The blog webpage was designed based on the PIXNET (https://www.pixnet.net/) because it is the popular blog platform used internationally, potentially reducing the reactions to the unfamiliar platforms (Kerlinger $\&$ Lee, 2000).

Before the formal experiment was performed, six types of traveling content (among 1000 words and three pictures) were randomly selected, and a pilot test (without using the eye-tracking device) was then conducted to examine which content was the most suitable in this study.

\section{Banner advertising}


This study chose a regular electronic product - a plain white Bluetooth Speakers as the advertising product for avoiding participants have subjective preferences toward specific products. We used a fictitious brand name (VS-sound) to prevent prior experience or word-of-mouth of real brands from exerting confounding effects (Dahlen, 2001). (see Figure 2)

\section{Figure 2. The Experimental Banner Advertising}

VS-sound

The best Bluctooth speakers for indoor and outdoor fun

Experimental advertising was composed of a brand name, an advertising claim, and a web address. This banner is typically a horizontal rectangle with dimensions of $468 \times 60$ pixels as the same as previous studies (Kuisma et al., 2010). Moreover, the advertising and webpage content differed from ensuring that the participants were not deceived or misled. The purpose of this study was to induce unconscious scanning behavior in response to banner advertising at the preattention stage. The original presentation and advertising type were not changed in the experiment to avoid confusing the participants. The banner advertising was embedded at the top of the webpage, which is the main spot that can attract users' attention effectively. The banner advertising was static, and the appeal focused on brand awareness to decrease any factors that can influence the participants' attention. Moreover, we also labeled the banner with the term "advertising."

\section{Manipulating the telic and paratelic states}

Telic states are usually query-based, with specific goals throughout the search process. Paratelic states can be viewed as navigating through hyperlinks which is usually no specific target exists (Bodoff, 2006). In fact, the typical task on the Internet is reading. The cognitive processing generated by reading is very different from other visual search cognitions(Rayner, Pollatsek, Liversedge, \& Reichle, 2009). Therefore, this study manipulates the purpose of the task by asking the participants to perform taskrelated reading behavior.

This study develops two scenarios to motivate participants to enter telic or paratelic states. For example, telic state is to requires the participants to search for tourism-related information at the site. That is, when participants are instructed, they will be asked to understand and collect the information on the browsing page. The paratelic states are to ask the participants to browse the websites as usual, without any tasks. The text mainly describes the instruction in this part. 
Before the formal experiment, this study recruited 30 participants to confirm the states are successfully manipulated for the pilot test (without using eye-tracker). A 12item inventory, based on the telic/paratelic state instrument originally developed by Calhoun (1996) was used to measure telic/paratelic state. Each item consisted of a 7point Likert scale anchored at each end by a pair of phrases denoting opposite feeling states.

\section{Apparatus}

To verify the apparatus minimally influenced and impeded the participants' behavior, the Mangold Vision EyeTracker was used in this study. This device has a nonintrusive apparatus featuring a minimal eyeball scanning frequency of $60 \mathrm{~Hz}$ and the capacity to calculate time in milliseconds. Moreover, an infrared camera and an image processing software suite that was used to present stimuli and conduct analyses. Therefore, participants did not have to wear any device on their head or eyes. Moreover, the computer program then analyzed the shape of the pupils and the position of the cornea borders to infer the participants' gaze plot and the movement of the gaze between fixations.

\section{Measurement}

Fixation time. The device provided an objective source of interface evaluation data and a continual measure of user reactions, such as fixation time (Rayner et al., 2009; Wedel \& Pieters, 2008). The fixation time points to the duration for which a gaze remains on a target block (area of interest, AOI), which was the area covered by banner advertising. A longer fixation time demonstrates a longer gaze duration. The unit of measurement used was the millisecond (ms).

\section{Advertising attitudes and website attitudes}

Advertising attitudes were measured using the scale developed by Chang and Thorson (2004). The participants responded to the statement 'I feel (this advertising) is...' by using four 7-point semantic differential items (anchored by very likable/very unlikable, interesting/not interesting, good/bed, appealing/not appealing). An average of scale items was used to form a composite measure of advertising attitudes (Cronbach's $\alpha=0.89$ in this study).

In addition, website attitudes were also adopted from the scale developed by Chang and Thorson (2004). The participants responded to the statement 'I feel (this website) is...' by using four 7-point semantic differential items (anchored by very likable/very unlikable, interesting/not interesting, good/bed, appealing/not appealing). (Cronbach's $\alpha=0.83$ in this study).

\section{Revisit intention}


The intention to revisit websites were based on McCoy et al. (2007), by using four 7-point semantic differential items (anchored by willing/unwilling to visit again, satisfied/unsatisfied, attractive/unattractive, high/low evaluation). (Cronbach's $\alpha=$ 0.81 in this study).

\section{Participants}

This study recruited volunteers into the experiment, and they were randomly assigned to one of the two groups. After deleting invalid subjects, a total of 146 participants completed the experiment, including 67 males and 79 females. The average age was 21.73 years $(S D=4.22)$. Most of the participants ( 87 percent) were 19 to 24 years old and had a university degree. The average Internet usage experience of the volunteers was 10.69 years $(S D=3.14)$, and their average Internet usage was $2.14 \mathrm{~h}$ per day $(\mathrm{SD}=1.53)$.

\section{RESULTS}

To verify H1, this study adopted regression analysis, revealing that the negative attitude towards the banner advertising will spill over to the host website, and then makes a negative attitude towards the host websites $\left(\beta=.39 ; p<.001 ; \Delta R^{2}=.39\right)$. Thus, $\mathrm{H} 1$ was supported. $\mathrm{H} 2$ indicated that when viewers have a negative attitude towards the host website, it will also reduce their fixation time, $\mathrm{H} 2$ was supported $(\beta=.52 ; p<.001$; $\Delta R^{2}=$.27). Moreover, the results also showed that when viewers have a negative attitude towards the host website, it will also reduce their revisit intention $(\beta=.61 ; p<.001$; $\Delta R^{2}=.37$ ), $\mathrm{H} 3$ was also supported. (see Table 1)

Table 1. Regression results of overall

\begin{tabular}{llllll}
\hline $\begin{array}{l}\text { Dependent } \\
\text { variable }\end{array}$ & $\begin{array}{l}\text { Independent } \\
\text { variable }\end{array}$ & $\beta$ & $t$ & $p$ & $\Delta R^{2}$ \\
\hline Website attitude & Advertising attitude & .39 & 5.08 & $.001^{*}$ & .39 \\
\hline Website attitude & Fixation time & .52 & 7.30 & $.001^{*}$ & .27 \\
\hline Revisit intention & Website attitude & .61 & 9.27 & $.001^{*}$ & .37 \\
\hline
\end{tabular}

Note: $\beta=$ beta coefficients; $\mathrm{t}=\mathrm{t}$-value; $\mathrm{p}=\mathrm{p}$-value.

$\mathrm{H} 4$ indicated that the negative attitude towards the advertising will significantly spill over to the websites in telic states. This study used an independent sample t-test and found that compared to paratelic states, viewers have spillover effect towards the host websites significantly when they are in telic states $(F=52.04 ; p<.001)$. This study also conducted an independent sample t-test to clarify that negative attitudes towards the websites will significantly reduce fixation time in telic states. The results showed 
that fixation time was significantly lower in telic states than in paratelic states $(F=70.54 ; p<.001)$. H5 was supported. H6 indicated that compared to paratelic states, viewers' revisit intention towards the host websites have significantly different when they are in telic states. This study conducted an independent sample t-test and showed that revisit intention was significantly lower in telic states than in paratelic states $(\mathrm{F}=17.26 ; \mathrm{p}<.001)$. H6 was also supported. (see Table 2$)$

Table 2. Independent Sample t-test Results of Overall

\begin{tabular}{lllllll}
\hline $\begin{array}{l}\text { Dependent } \\
\text { variable }\end{array}$ & $\begin{array}{l}\text { Independent } \\
\text { variable }\end{array}$ & $n$ & $M$ & $S D$ & $F$ & $p$ \\
\hline Website & telic states & 61 & 2.31 & .10 & 52.04 & $.001^{*}$ \\
attitude & paratelic states & 85 & 3.21 & .07 & & \\
\hline Fixation & telic states & 61 & 471.54 & 53.74 & 70.54 & $.001^{*}$ \\
time & paratelic states & 85 & 2345.35 & 184.86 & & \\
\hline Revisit & telic states & 61 & 2.22 & .11 & 17.26 & $.001^{*}$ \\
intention & paratelic states & 85 & 2.84 & .09 & & \\
\hline
\end{tabular}

Note: $\mathrm{N}=$ number of participants; $\mathrm{M}=$ mean; $\mathrm{SD}=$ standard deviation; $\mathrm{F}=\mathrm{F}$-value; $\mathrm{p}=\mathrm{p}$-value

\section{CONCLUSIONS}

\section{Discussion}

Based on the spillover effect and reversal theory, this study proposed that viewers will serve banner advertising as contextual clues to judge the host websites. Once exposure to annoying advertising, viewers are not only conscious or unconscious adopting the avoid behavior towards the advertising, this negative attitudes will also spill over onto the host websites. This study conducted a laboratory experiment to build a realistic website and banner advertising to measure viewers' browsing behavior, advertising, and website attitude, and revisit intention. Moreover, because the browsing behavior is unconscious, this study recorded this behavior by using the eye-tracking device.

The results showed that the negative attitudes generated by banner advertising do spill over to the host websites, which in turn negatively affects the website. The websites may also evoke similar feelings and perceptions as those generated by banner advertising, which is consistent with a previous study (Thota et al., 2012). In other words, when viewers subconsciously browse the block of the advertising, the cognitive resources are consumed, and the task is hinder simultaneously.

When viewers have negative attitudes toward the host websites, their fixation time and revisit intention of the websites will be significantly reduced. The possible reason is that viewers will recognize that managers are profit-oriented, so it put in multiple 
advertising content and reduces the speed of opening and executing the website. At this time, viewers think that managers do not pay attention to manage the content on this site. Therefore, they are more likely to search for another site to gain useful information. Therefore, when viewers have negative emotion and attitude towards the host websites, in addition to the bad and angry feeling (Burns \& Lutz, 2006; Gao et al., 2004), it may also reduce the willingness to revisit the websites (McCoy et al., 2007).

Moreover, the findings also suggested that when viewers are in telic states, the negative attitude towards advertising will spill over significantly, and then reduce their fixation time and revisit intention towards the website.

\section{Theoretical Implications}

The results of this study have several theoretical implications. First of all, previous studies are mostly based on the perspective of advertising avoidance, and further provided the reference for the advertisers. This study believed that website managers should think more about the possible impact of these banner advertising on host websites. This is important for website managers, especially when they want to increase the viewers' staying time and possible attitude. Therefore, website managers need to make a trade-off between short-term cash flow and ensure an appropriate website image in viewers' minds.

Second, continue to this concept, this study used the spillover effect to provide a new direction. The results showed that banner advertising perceived unfavorably actually harm host websites and may reduce future traffic and revisit intention. Third, the basis of metamotivational states refers that when viewers are in telic states, they need to spend more effort on the specific content. Once they have a negative attitude towards advertising, it will affect the browsing behavior more significantly. Finally, this study used eye-tracking device and attitude scales to obtain more accurate and complete browsing behavior data, which can be the reference for subsequent research.

\section{Practical Implications}

The findings of this study provide practical suggestions for website managers and advertisers. First, managing viewers' negative emotional responses on the Internet is critical for website designers and marketers. Although most websites need to rely on the revenue generated by banner advertising, managers also need to make a trade-off between the advertising that may be perceived as irritating and ridiculous to increase short-term cash flow. Even viewers know that the next time they visit the websites, there will be other ads. They still have a specific website-advertising combination, so that makes the negative attitude to the website. 
Second, managers need to carefully select the type and content of banner advertising to reduce the influence of the irritated with unfavorable banner advertising. For example, they need to determine which types of advertising are more suitable for their websites. Viewers could perceive banner advertising as helpful if these are in consonance with their online activity.

Third, the advertising platform managers can follow the results from this study that select more appropriate advertising to embed in the host websites. They can also help to evaluate the quality of advertising and their content. Moreover, since each website has very specific data (from google analytics) that can be utilized for targeted ads, the relevance and value of advertising to viewers can be increased several times if the execution of specific targeting is done appropriately.

\section{Limitations and Directions for Future Studies}

This study conducted a laboratory experiment to avoid too many external environmental factors affecting the variables. However, the searching situation plays a vital role in online search, which can influence the results. Future researchers may consider other scenarios for the experiment. Moreover, this study mainly explores the general form of websites. However, there is more advertising that has been placed on social media in recent years. Therefore, future research can extend the concept of this study and further explore the perspective on social media. Whether enhancing the relevance of advertising could reduce its negative effects on websites could be explored in future research.

Moreover, although this study discussed the viewers' metamotivational states, we did not focus on their purchase intention directly. Further, researchers can explore the role of advertising content on realistic purchase intention. Fourth, this study used an eye-tracking device to examine browsing behavior. Future research can obtain actual data of advertising interaction status, which may be able to verify the validity of the results.

\section{REFERENCES}

Balachander, S., \& Ghose, S. (2003). Reciprocal spillover effects: A strategic benefit of brand extensions. Journal of Marketing, 67(1), 4-13.

https://doi.org/10.1509/jmkg.67.1.4.18594

Baltas, G. (2003). Determinants of internet advertising effectiveness: An empirical study. International Journal of Market Research, 45(4), 1-9. https://doi.org/10.1177/147078530304500403

Belanche, D., Flavián, C., \& Pérez-Rueda, A. (2017). Understanding interactive online advertising: Congruence and product involvement in highly and lowly arousing, 
skippable video ads. Journal of Interactive Marketing, 37, 75-88. https://doi.org/10.1016/j.intmar.2016.06.004

Boateng, H. (2016). Customer knowledge management practices on a social media platform: A case study of MTN Ghana and Vodafone Ghana. Information Development, 32(3), 440-451. https://doi.org/10.1177/0266666914554723

Bodoff, D. (2006). Relevance for browsing, relevance for searching. Journal of the American Society for Information Science and Technology, 57(1), 69-86. https://doi.org/10.1002/asi.20254

Burns, K. S., \& Lutz, R. J. (2006). The function of format: Consumer responses to six on-line advertising formats. Journal of advertising, 35(1), 53-63. https://doi.org/10.2753/joa0091-3367350104

Chang, Y., \& Thorson, E. (2004). Television and web advertising synergies. Journal of Advertising, 33(2), 75-84. https://doi.org/10.1080/00913367.2004.10639161

Chiang, I. P., Lo, S. H., \& Wang, L.-H. (2017). Customer engagement behaviour in social media advertising: Antecedents and consequences. Contemporary Management Research, 13(3), 193-216. https://doi.org/10.7903/cmr.17673

Chiu, Y.-P. (2019). Do social and competitive advergames affect brand attitude in Asia? International Journal of Electronic Commerce Studies, 10(1), 23-41. https://doi.org/10.7903/ijecs.1722

Chiu, Y.-P., Lo, S.-K., \& Hsieh, A.-Y. (2017). How colour similarity can make banner advertising effective: Insights from Gestalt theory. Behaviour \& Information Technology, 36(6), 606-619. https://doi.org/10.1080/0144929x.2016.1267264

Cho, C.-H., \& Cheon, H. J. (2004). Why do people avoid advertising on the internet? Journal of Advertising, 33(4), 89-97. https://doi.org/10.1080/00913367.2004.10639175

Dahlen, M. (2001). Banner advertisements through a new lens. Journal of advertising Research, 41(4), 23-30. https://doi.org/10.2501/jar-41-4-23-30

Deng, L., \& Poole, M. S. (2010). Affect in web interfaces: A study of the impacts of web page visual complexity and order. Mis Quarterly, 34(4), 711-730. https://doi.org/10.2307/25750702

Djamasbi, S., Siegel, M., \& Tullis, T. (2010). Generation Y, web design, and eye tracking. International Journal of Human-Computer Studies, 68(5), 307-323. https://doi.org/10.1016/j.ijhcs.2009.12.006

Duff, B. R., \& Faber, R. J. (2011). Missing the mark. Journal of Advertising, 40(2), 5162. https://doi.org/10.2753/joa0091-3367400204

Faber, R. J., Lee, M., \& Nan, X. (2004). Advertising and the consumer information environment online. American Behavioral Scientist, 48(4), 447-466. https://doi.org/10.1177/0002764204270281 
Gao, Y., Koufaris, M., \& Ducoffe, R. H. (2004). An experimental study of the effects of promotional techniques in web-based commerce. Journal of Electronic Commerce in Organizations (JECO), 2(3), 1-20. https://doi.org/10.4018/jeco.2004070101

Greenwald, A. G., \& Leavitt, C. (1984). Audience involvement in advertising: Four levels. Journal of Consumer Research, 11(1), 581-592. https://doi.org/10.1086/208994

Ha, L., \& McCann, K. (2008). An integrated model of advertising clutter in offline and online media. International Journal of Advertising, 27(4), 569-592. https://doi.org/10.2501/s0265048708080153

Harrar, V., Le Trung, W., Malienko, A., \& Khan, A. Z. (2018). A nonvisual eye tracker calibration method for video-based tracking. Journal of Vision, 18(9), 13, 1-11. https://doi.org/10.1167/18.9.13

Hsu, C.-L., Chang, K.-C., Kuo, N.-T., \& Cheng, Y.-S. (2017). The mediating effect of flow experience on social shopping behavior. Information Development, 33(3), 243-256. https://doi.org/10.1177/0266666916651918

Hussain, R., Ferdous, A. S., \& Mort, G. S. (2018). Impact of web banner advertising frequency on attitude. Asia Pacific Journal of Marketing and Logistics. https://doi.org/10.1108/apjml-04-2017-0063

Hwang, Y., \& Jeong, J. (2016). Electronic commerce and online consumer behavior research: A literature review. Information Development, 32(3), 377-388. https://doi.org/10.1177/0266666914551071

Janiszewski, C. (1998). The influence of display characteristics on visual exploratory search behavior. Journal of consumer research, 25(3), 290-301. https://doi.org/10.1086/209540

Kang, M. Y. (2019). Advertising allocation and impact of advertising on event ticket sales: Which product, where, and when. International Journal of Market Research, 1470785319835380. https://doi.org/10.1177/1470785319835380

Keppel, G. (1991). Design and analysis: A researcher's handbook: Prentice-Hall, Inc.

Kerlinger, F., N, \& Lee, H., B. (2000). Foundations of behavioral research. New York.

Kim, S., Youn, S., \& Yoon, D. (2019). Consumers' responses to native vs. banner advertising: Moderation of persuasion knowledge on interaction effects of ad type and placement type. International Journal of Advertising, 38(2), 207-236. https://doi.org/10.1080/02650487.2018.1451208

Kuisma, J., Simola, J., Uusitalo, L., \& Öörni, A. (2010). The effects of animation and format on the perception and memory of online advertising. Journal of Interactive Marketing, 24(4), 269-282.

https://doi.org/10.1080/02650487.2018.1451208 
Lee, J., \& Ahn, J.-H. (2012). Attention to banner ads and their effectiveness: An eyetracking approach. International Journal of Electronic Commerce, 17(1), 119137. https://doi.org/10.2753/jec1086-4415170105

Li, H., Edwards, S. M., \& Lee, J.-H. (2002). Measuring the intrusiveness of advertisements: Scale development and validation. Journal of Advertising, 31(2), 37-47. https://doi.org/10.1080/00913367.2002.10673665

Lin, Y., Zhang, W., \& Watson, L. (2003). Using eye movement parameters for evaluating human-machine interface frameworks under normal control operation and fault detection situations. International Journal of HumanComputer Studies, 59(6), 837-873.

https://doi.org/10.1016/s1071-5819(03)00122-8

Lohtia, R., Donthu, N., \& Hershberger, E. K. (2003). The impact of content and design elements on banner advertising click-through rates. Journal of Advertising Research, 43(4), 410-418. https://doi.org/10.2501/jar-43-4-410-418

McCoy, S., Everard, A., Polak, P., \& Galletta, D. F. (2007). The effects of online advertising. Communications of the ACM, 50(3), 84-88.

https://doi.org/10.1145/1226736.1226740

Moors, A., \& De Houwer, J. (2006). Automaticity: A theoretical and conceptual analysis. Psychological Bulletin, 132(2), 297-326. https://doi.org/10.1037/0033-2909.132.2.297

Mulvey, F., Zemblys, R., Larsson, L., \& Holmqvist, K. (2014). Clarifying the validity of eye movement measures from various eye tracker types; A systematic study of data quality, event detection algorithms and filters. Vision Sciences Society Annual Meeting Abstract, 14(10), 755-755. https://doi.org/10.1167/14.10.755

Namin, A., Hamilton, M. L., \& Rohm, A. J. (2020). Impact of message design on banner advertising involvement and effectiveness: An empirical investigation. Journal of Marketing Communications, 26(2), 115-129. https://doi.org/10.1080/13527266.2017.1393767

O’Connell, K. A., \& Calhoun, J. E. (2001). The telic/paratelic state instrument (T/PSI): validating a reversal theory measure. Personality and Individual Differences, 30(2), 193-204. https://doi.org/10.1016/s0191-8869(00)00026-x

Olivers, C. N., \& Humphreys, G. W. (2002). When visual marking meets the attentional blink: More evidence for top-down, limited-capacity inhibition. Journal of Experimental Psychology: Human Perception and Performance, 28(1), 22-42. https://doi.org/10.1037/0096-1523.28.1.22

Putrevu, S., \& Lord, K. R. (2003). Processing Internet communications: A motivation, opportunity and ability framework. Journal of Current Issues \& Research in Advertising, 25(1), 45-59. https://doi.org/10.1080/10641734.2003.10505140 
Rayner, K., Pollatsek, A., Liversedge, S. P., \& Reichle, E. D. (2009). Eye movements and non-canonical reading: Comments on. Vision Research, 49(17), 2232-2236. https://doi.org/10.1016/j.visres.2008.10.013

Romaniuk, J., \& Wight, S. (2009). The influences of brand usage on response to advertising awareness measures. International Journal of Market Research, 51(2), 1-13. https://doi.org/10.1177/147078530905100213

Ryu, G., Lim, E. A. C., Tan, L. T. L., \& Han, Y. J. (2007). Preattentive processing of banner advertisements: The role of modality, location, and interference. Electronic Commerce Research and Applications, 6(1), 6-18. https://doi.org/10.1016/j.elerap.2005.11.001

Stafford, T. F., \& Stafford, M. R. (2002). The advantages of atypical advertisements for stereotyped product categories. Journal of Current Issues \& Research in Advertising, 24(1), 25-37. https://doi.org/10.1080/10641734.2002.10505125

Stanaland, A. J., \& Tan, J. (2010). The impact of surfer/seeker mode on the effectiveness of website characteristics. International Journal of Advertising, 29(4), 569-595. https://doi.org/10.2501/s026504871020135x

Tangmanee, C. (2016). Fixation and recall of YouTube ad banners: An eye-tracking study. International Journal of Electronic Commerce Studies, 7(1), 49-76. https://doi.org/10.7903/ijecs.1404

Thota, S. C., Song, J. H., \& Biswas, A. (2012). Is a website known by the banner ads it hosts? Assessing forward and reciprocal spillover effects of banner ads and host websites. International Journal of Advertising, 31(4), 877-905. https://doi.org/10.2501/ija-31-4-877-905

Voorveld, H. A., van Noort, G., Muntinga, D. G., \& Bronner, F. (2018). Engagement with social media and social media advertising: The differentiating role of platform type. Journal of Advertising, 47(1), 38-54. https://doi.org/10.1080/00913367.2017.1405754

Wedel, M., \& Pieters, R. (2008). A review of eye-tracking research in marketing. Review of marketing research, 4, 123-147. https://doi.org/10.1108/s1548-6435(2008)0000004009

Zhang, L., Luo, M., \& Boncella, R. J. (2020). Product information diffusion in a social network. Electronic Commerce Research, 20, 3-19.

https://doi.org/10.1007/s10660-018-9316-9

Yu-Ping Chiu (Corresponding author) is an assistant professor of Advertising Department at the Chinese Culture University, Taiwan. He received his Ph.D. in Marketing in 2014. His research interests include online word-of-mouth, electronic commerce, and 
computer-mediated communication. He has published articles in Online Information Review, Internet Research, Computers in Human Behavior, Information Development, International Journal of Electronic Commerce, Electronic Commerce Research and Applications.

Shu-Chen Chang is an assistant professor of Advertising Department at the Chinese Culture University, Taiwan. She received his Ph.D in Information Management in 2015. Her research interests include advertising technology, online advertising, e-commerce, and internet marketing technology. She has published articles in Journal of Business Research, Information Development, and Cyberpsychology, Behavior, and Social Networking. 